\title{
The Creativity Model of Age and Innovation with IT: How to Counteract the Effects of Age Stereotyping on User Innovation
}

\author{
Stefan Tams \\ HEC Montréal \\ stefan.tams@hec.ca
}

\author{
Alina Dulipovici \\ HEC Montréal \\ alina.dulipovici@hec.ca
}

\begin{abstract}
Older users shy away from the post-adoptive use of information technologies much more often than their younger counterparts. This situation is alarming given that the workforce is aging rapidly and that organizational technologies are proliferating at the same time. Yet there is no clear explanation for older users' lower post-adoptive use, which limits practitioners' understanding of what can be done to assist them. This lack of understanding is especially problematic vis-à-vis user innovation. Successful firms like Microsoft, 3M, or Nike encourage their employees to innovate with IT in order to realize the full potential of their existing IT infrastructure. Thus the present paper advances the creativity model of age and innovation with IT. This model indicates that age differences in user innovation are accounted for by negative age stereotypes and their impacts on creative IT self-efficacy. The model further proposes that the indirect effect of age through creative IT self-efficacy on user innovation can be lessened by contextual factors, namely job control, IT support, and user enjoyment. The paper offers much-needed implications both for managers and for systems designers.
\end{abstract}

\section{Introduction}

Bonnie has just turned 61 years old. To support her work as a marketing manager, she has to use an evergrowing variety of ever more modern IT. Like many older workers, she has a positive attitude toward IT. Yet she finds it difficult to take full advantage of it. For example, she does not try to identify novel ways in which to apply the technology to her work, although doing so could improve her job performance. Bonnie's younger co-manager Clyde, by contrast, constantly discovers new ways of exploiting the available IT to do his job better. Bonnie and Clyde's superior manager is pleased to notice that Clyde helps the organization realize more value from its IT investments. However, he wonders why Bonnie does not try to be as innovative with IT as Clyde is, and he would like to better understand what to do about that.
Bonnie and Clyde's case illustrates two trends that are emerging in OECD countries: (1) the "graying" of the workforce and (2) the unescapable growth of IT in organizations [1]. As regards the former, the populations and the workforces in OECD countries are growing older fast [2]. To be precise, the number of older workers (i.e., workers who are 60 years of age and over) climbed from 15,906,000 in 2000 to $24,548,000$ in 2012 in OECD countries, an increase of more than $50 \%$ [1]. For example, today university faculty often work far beyond the age of 65 [3]. The OECD expects this trend to continue: older persons will participate in the workforce at sharply increasing rates over the next several decades. There are various reasons that motivate individuals to stay in the workforce longer, including economic factors like maintaining a higher standard of living and later retirement ages in many OECD countries [4,5].

With respect to IT use in organizations, Benbasat and Zmud [6] note that computer technology has a tendency to evolve at an astonishing rate. From the introduction of desktop PCs on through to more recent technologies like personal digital assistants (PDA), IT has evolved from bulky user-'unfriendly' terminals to "intelligent" smartphones and highly sophisticated Voice-over-IP applications. To avoid falling behind, organizations do not have a choice but to constantly make substantial IT investments. For example, an ERP implementation averages total costs of 17 million dollars and can easily cost hundreds of millions for larger firms [7]. To justify these costs and generate high returns, IT applications should be fully utilized. However, the functional potential of the installed IT applications often remains underutilized, implying a lack of post-adoptive use $[8,9]$. This means that many users apply a narrow band of features and rarely initiate extensions of the available features [8]. To counteract this problem and realize the full potential of their existing IT infrastructure, many successful firms such as Microsoft, 3M, or Nike encourage their employees to innovate with IT [10]. Indeed, user innovation has been found to be an especially effective form of post-adoptive use [10,11]. 
Consistent with the seminal work of Ahuja and Thatcher [10], we conceptualize and operationalize user innovation (and its synonyms "trying to innovate with IT" and "innovation with IT") as a user's goal of finding new uses of existing workplace information technologies. User innovation requires, above all, creativity [10]. Creativity is the generation of novel and useful ideas [12], for example ideas about new ways of using an IT to get a job done. As such, creativity is the prerequisite to innovation, which is the implementation of said new ideas [12].

When it comes to creativity and older workers, managers often hold the firm belief that older workers are less creative [13]. This negative age stereotype is false [14], yet it is so pervasive that even older workers themselves often believe in it [17]. As a result, older workers often falsely assume an inability to be creative [15] that discourages them from innovating $[10,13]$. In the context of IT-related work, the problems related to older workers' creativity and innovation that arise from negative age stereotyping are especially pronounced [16]. Older workers are often seen as less adaptive to new systems and as less innovative than their younger colleagues [16].

In reality, older workers have become more open to modern technologies and are increasingly online [19]. However, their IT use has remained qualitatively different from that of younger users [17]. In particular, older users often limit their technology usage to a few core features rather than trying to expand the variety of their use experiences [17]. This has been demonstrated empirically in the context of self-service checkouts [18]. While the qualitatively different form of technology use between older and younger persons has a strong link to cognitive aging, it is also related to negative age stereotypes about technology use [19,20]. Not only do managers and coworkers hold negative stereotypes against older users, but even the older user does not often believe in their very own ability to go beyond the use of core features. They often simply excuse themselves with the line "I'm too old," which has become a self-explanatory justification [17].

Research has yet to develop an in-depth understanding of older users' innovation with IT. Thus far, research has focused on the general connection between the two constructs, that is to say, on the direct effect. For example, Lee et al. [18] find that user innovation decreases as age increases $(\beta=-0.18$, $\mathrm{p}<0.01)$. This finding has greatly improved our understanding of the relationship between age and post-adoption in general, and between age and user innovation in particular. Current research needs to build on this finding and on related ones in the literature by identifying more specific explanations for the observed age effects. What is needed is a thorough examination of the scientific foundation of conclusions about age differences in user innovation. In other words, we need to bring into focus the structure of the relationship between a user's age and the user's goal to innovate with IT. This will help explain the link between age and user innovation more fully, and it will enable us to clarify the theoretical nature of the observed age effects.

To this end, two interrelated research questions have to be examined. The first one concerns the question of why older users are less innovative with IT. Research has yet to establish an explanation for this important relationship. This requires an investigation based on a mediation model that would identify the mechanism by which age impacts user innovation. Thus using mediation concepts and analysis the first goal of the present paper is to begin developing a more adequate explanation of why older users do not innovate as much with IT as younger ones.

Moreover, as Tams et al. [20] have shown, knowing why older users innovate less is of limited value without an understanding of what can be done to assist them. In other words, determining what can be done to help older users remain productive workers is a closely related issue. Consequently, the second goal of the present paper is to examine whether certain contextual factors can moderate the problem for older users. Moderated mediation analysis is required to examine research question 2 in conjunction with research question 1 and to arrive at an integrative, more holistic understanding of the relationship between age and user innovation.

Both research objectives concern pressing issues. IT researchers have been calling for an in-depth examination of the impact of age on use-related outcomes for some time. In particular, they have emphasized the need to identify the "underlying influential mechanisms" that produce the observed effects (e.g., [21,20,22, p.469]). Only a few researchers have heeded this call and used general theories of cognitive psychology, such as the theory of planned behavior and social cognitive theory, to improve understanding of these underlying influential mechanisms [23,24]. We need to build on this pioneering work by adopting theories of aging [20]. These theories can provide more specific explanations of age differences in IT usage. Thus they are more likely to elucidate some of the underlying influential mechanisms and, as a result, to advance our theoretical understanding of age-related impacts on IS outcomes.

This study makes several important contributions to IT research. It shows that a mediation model can improve our understanding of the link between age and user innovation by identifying the specific mechanism that explains this link. A clear and empirically- 
validated understanding of this explanatory mechanism would enable IT researchers to provide improved support both to managers and to systems designers.

Second, by examining use conditions that can moderate the problem for older users, we make it possible to identify means of assisting them. This is crucial information for managers who have to determine how to allocate limited resources in the most effective manner. Moreover, understanding which factors can moderate the problem for older users is important for developing appropriate intervention strategies. We can also inform systems designers more effectively of how to design user interfaces with both younger and older users in mind.

In addition, our study contributes to research on post-adoptive technology use. Seminal research on post-adoption has described individual differences like age as major factors in explaining differences in the extent to which workers (under-) utilize technologies [8]. Our study contributes to this important line of inquiry by theorizing and empirically evaluating the role that age plays in user innovation.

The paper is structured as follows. The next section introduces the Creativity Theory of Aging from the field of industrial and organizational psychology. This theory allows us to examine our two research questions concurrently. The theory integrates an explanation for age differences in innovation with important moderators of this relationship. Thus the theory allows us to frame a parsimonious research model of age differences in user innovation. The third section applies the Creativity Theory of Aging to develop the research hypotheses. Then, we outline the proposed methodology that will be employed to test the hypotheses. Finally, we discuss the contributions expected from this work for research and for practice.

\section{Theoretical Background}

Prior research has provided ample evidence that older adults face greater difficulties using IT [27,21, 28,29]. While older workers no longer resist information technologies - in fact, older persons are the fastest-growing group of internet users - they still use them in qualitatively different ways than their younger counterparts [17]. For example, older workers often use basic features only and generally limit both the breadth and the depth of their IT usage. This means that, in a graying workforce, organizational IT remains underutilized. Lack of user innovation is a particularly important problem because innovation with IT has strong links to firm success [10].

Prior research has focused on the direct relationship between age and IT usage. In doing so, it has substantively advanced our understanding of agerelated effects, showing that age influences how effectively people use IT. For example, Venkatesh et al. [29] show that older workers are less likely than younger ones to use portals. Indeed, these authors make a strong contribution to our understanding of the impact of age on workers in IT settings, for they provide important evidence that older users are less efficient when they have to work with IT.

Following Tams et al. [20] and Venkatesh et al. [22], current research needs to build on this important insight through an in-depth examination of the underlying causes of the difficulties that older users have with IT. In other words, the "underlying influential mechanism" that leads to these difficulties has to be brought to light [22, p.469]. This means that current research needs to find a precise theoretical explanation for why age impacts user innovation. Offering broad speculations and/or focusing on sensemaking will not suffice. Another important shortcoming of current research is that it has not yet explored the boundary conditions (i.e., the moderators) for the age-IT relationship [20]. In a word, research needs to move away from the search for general explanations of the relationship between age and user innovation, and attempt to provide detailed accounts of the specific factors that determine it.

To obtain deeper insight, current work needs to find a more nuanced theory that is specific to aging [20]. The Creativity Theory of Aging [13] seems especially relevant. This deduction is based on Truex et al.'s [30] four considerations for adapting theories from other domains to IT research. These four considerations are:

(1) the fit between selected theory and phenomenon of interest,

(2) the theory's historical context and underlying assumptions,

(3) how the theory impacts the choice of research method, and

(4) the contribution of theorizing to cumulative theory.

First of all, the theory is applicable to the phenomenon of interest. The theory's independent variable is age and its dependent variable is creativity, a prerequisite for innovation in general and for user innovation in particular [10]. This is also the independent-dependent variable pair of interest to our study. The theory further proposes that certain factors can mitigate the problem for older users. Specifically, job control and support for creativity are proposed as moderators that can lessen the extent to which age reduces creativity and innovation [13]. Thus, the constructs and relationships proposed in the Creativity Theory of Aging fit the phenomenon of interest here. 
As regards the theory's historical context and underlying assumptions, the theory aims at explaining various phenomena related to age, creativity, and innovation. It makes one main assumption: it assumes that the relationship between age and idea creativity is moderated by contextual factors. IT researchers have long acknowledged the importance of contextual factors when studying age-related impacts on IT use $[23,20]$. Thus the theory's assumptions are consistent with IT research.

As regards the research method and data-analytic procedure for the Creativity Theory of Aging, the theory relies on survey research and moderation analysis in multiple regression. It follows the positivist research tradition. Positivism and quantitative methods, including regression analysis, also have a long tradition in IT research. Therefore, the ontological and epistemological presuppositions as well as the methods and data-analytic techniques employed to test the predictions of the Creativity Theory of Aging are consistent with the traditions in IT research.

Finally, to make a contribution to cumulative theory, any application of the Creativity Theory of Aging has to allow us to go beyond the already known. As mentioned earlier, past research has demonstrated a strong direct link between age and adoption, but it has not sufficiently clarified why older workers are less likely to adopt and innovate and what factors might lessen this problem. The Creativity Theory of Aging allows us to fill this important gap.

In summary, the Creativity Theory of Aging is a good fit for our research questions and domain. The central thesis of the theory is twofold: increased age in adulthood is associated with a decrease in creativity and innovation, and this reduction can be moderated by contextual factors [13]. We will use the constructs and relationships the theory proposes to specify our research model.

\section{Hypotheses Development}

Based on the Creativity Theory of Aging, we propose a moderated mediation model of age, creativity, user innovation, and contextual factors. Specifically, our research model hypothesizes that agerelated stereotyping causes a decline in creative selfefficacy which, in turn, reduces user innovation (see Figure 1). The model further proposes that age-related impacts on user innovation can be mitigated by three contextual factors: job control, IT support, and user enjoyment. To develop formally this research model, we first conceptualize the causal link between age and user innovation (research question 1). Then, we refine this baseline model by elucidating the moderating factors that managers and systems designers need to be aware of to control age-related impacts on innovativeness with IT (research question 2).

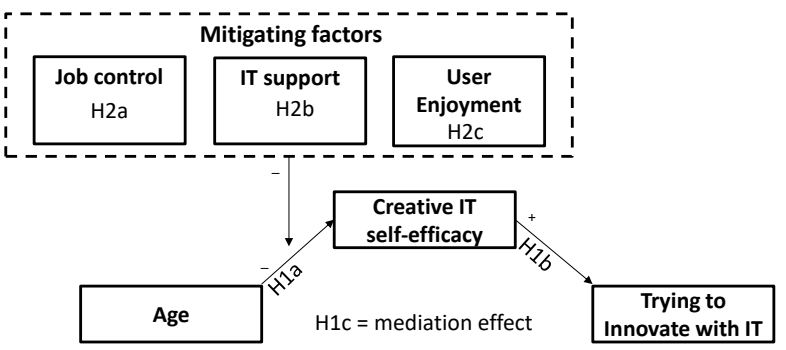

Figure 1. Our research model entitled "The creativity model of age and innovation with IT"

\section{Baseline mediation model}

When applying the Creativity Theory of Aging to the study of user innovation, one can deduce the hypothesis that negative age stereotypes lead to deteriorations in creative IT self-efficacy. These deteriorations, in turn, impair innovativeness with IT. Further analysis of the Creativity Theory of Aging follows, along with the hypotheses formalizing our baseline model. Hypotheses $1 \mathrm{a}$ and $1 \mathrm{~b}$ are offered for reasons of completeness only; our main focus is on Hypothesis 1c.

We explain and justify the link between age and creative IT self-efficacy with the notion of negative age stereotyping. In other words, negative age stereotyping is not a construct in our research model. Instead, it is the basis of our hypothesis justification; it explains why age and creative IT self-efficacy are related.

Negative age stereotyping is common, especially in the context of IT-related work [16]. Age stereotypes are socially-shared beliefs about the abilities and behaviors that members of a specific age group have in common [33]. Stereotypes are often negative. According to the stereotype content model, older workers in particular are seen as low in competence. These stereotypes are learned through socialization and, thus, can shape social behavior considerably. For example, stereotypes frequently lead to discrimination against older workers [34]. Such discriminatory behavior often occurs on a pre-conscious level so that persons who discriminate against older workers are not always aware of it.

One especially persistent and widespread negative age stereotype is that older workers are less innovative [35]. This age stereotype has also been found empirically in organizations (e.g., [18]). This does not mean that every older worker is less innovative than every younger worker but that older workers are less 
innovative on average, as an aggregate. That being said it is crucial to note that older workers are not less innovative per se. Instead, the stereotype that older workers are less innovative holds true because it is a self-fulfilling prophecy, a false prediction that evokes corresponding beliefs and thereby causes the originally false prediction to become true: since older workers face numerous negative stereotypes and have usually even held these stereotypes themselves long before becoming older, over time the stereotypes have become ingrained in them [36].

Indeed, negative age stereotypes are learned early in life through socialization and reinforced later in life through coworkers. This means that the confidence of older workers in their own abilities is reduced, with sometimes dramatic consequences. For example, older persons who have held more negative age stereotypes earlier in life are significantly more at risk to develop Alzheimer's disease [37]. Due to their reduced confidence in their own abilities later in life, they demonstrate significantly steeper brain losses than those who do not have reduced confidence in their own abilities.

Confidence is reflected in self-efficacy, which refers to individuals' beliefs in their ability to be successful in a specific domain or situation. The Creativity Theory of Aging holds that negative age stereotypes lead older workers to have lower selfefficacy regarding their creativity at work. In other words, they have less creative self-efficacy. In the context of user innovation, this means that older workers should have lower creative IT self-efficacy, which refers to individuals' beliefs in their ability to use a technology in creative ways to get their work done [38,39]. Therefore:

Hla: Age is negatively related to Creative IT selfefficacy.

The Creativity Theory of Aging and seminal research on creativity indicate that creative selfefficacy has strong links to creativity and innovation $[12,13,40]$ Self-efficacy motivates workers to make a greater effort to achieve desired outcomes. Creative endeavors like innovation require an internal, sustaining force that pushes individuals to persist in the face of the various challenges that are native to creative work [40]. Bandura [41] also points out that strong efficacy beliefs enhance the persistence that individuals will show when encountering challenging situations.

The relationship between self-efficacy and use behavior is well established in the IT literature as well $[42,43,44]$. Consistent with seminal research on selfefficacy (e.g., [41,45]), IT research has argued that computer self-efficacy leads individuals to make a greater effort towards the effective use of technologies and to be more persistent in the face of challenging use situations like trying to innovate with IT [43]. Such research has also argued that individuals high in computer self-efficacy set higher goals for themselves regarding the use of technologies and that they are more committed to reaching those goals. Since we conceptualized user innovation as a goal-based construct, it is clear that higher goal levels and greater levels of goal commitment have direct impacts on it. This deduction may hold especially true for creative IT self-efficacy which, compared to computer selfefficacy, is more specific and relevant to user innovation [38,39].

In addition, elevated self-efficacy levels lead to changes in how individuals approach cognitive tasks like trying to innovate with IT. These changes include broader information search and greater memory recall, both of which improve creativity and innovation [40]. Thus we propose:

$H 1 b$ : Creative IT self-efficacy is positively related to a user's goal to innovate with IT.

As regards the causal order of the constructs, the Creativity Theory of Aging holds that negative age stereotypes lead older workers to have reduced creative self-efficacy. Creative self-efficacy, in turn, is a strong predictor of worker creativity and innovation $[13,40]$. This means that creative IT self-efficacy should mediate the impact of age on user innovation. Consistent with this mediation hypothesis, we argue that age per se cannot be expected to cause decrements in user innovation. Instead, it is the reduction in creative IT self-efficacy that causes declines in user innovation, and age is responsible for this reduction.

Moreover, individual differences can represent cognitive or non-cognitive predictors, and these predictors can be conceptually proximal or distal from behavior [46,47]. Non-cognitive predictors are considered to be conceptually distal from behavior, whereas cognitive ones are close to behavior. This has been demonstrated in studies that observed noncognitive and cognitive predictors concurrently [48]. It can also be inferred from research confirming that cognitive predictors substantively reduce or even eliminate age-related variance in behavior, whereas non-cognitive ones are not nearly as effective in doing so [49]. Age is a non-cognitive predictor (a user's demographic), whereas self-efficacy is a cognitive one [46]. Therefore, creative IT self-efficacy is conceptually closer to behavior than age is.

To extend this line of reasoning, age per se is unlikely to place fundamental limits on creativity and innovation, in contrast to creative self-efficacy. There is nothing about age, per se, that prevents older users 
from being creative. By contrast, deteriorations in creative self-efficacy beliefs will impose major limits on creativity and innovation. As argued earlier in this paper, this is because declines in creative self-efficacy beliefs entail corresponding declines in motivation as well as in effort, and because they result in a narrowed information search and in diminished memory recall. Thus creative IT self-efficacy is more immediately relevant to innovation than age is.

In a word, proximal cognitive predictors, especially self-efficacy, often mediate the impact of more distal non-cognitive ones like age on behavior [46,50]. This deduction is consistent with IT research arguing that age is antecedent to computer self-efficacy which, in turn, is an antecedent of computer-related behaviors [43]. Therefore:

Hlc: There is a negative, indirect effect of age through creative IT self-efficacy on a user's goal to innovate with IT. In other words, creative IT selfefficacy mediates the negative effect of age on user innovation.

According to the Creativity Theory of Aging, contextual factors can moderate the effect for older workers. The theory specifies two such factors: job control and support for creativity. Thus we suggest that job control and support for creativity can buffer against age-related declines in creative IT self-efficacy. A high degree of job control indicates to employees that they are believed capable of successfully fulfilling their work tasks. This indication runs counter to the negative age stereotypes that older workers often hold against themselves. As a result, the negative impact of age on creative IT self-efficacy and innovation is weakened. By contrast, a low degree of job control is in agreement with the negative age stereotypes that older workers often hold against themselves. Thus it will be interpreted by older workers as a confirmation of their inability to generate new ideas about how to use an IT. As a result, the negative impact of age on creative IT self-efficacy and innovation is strengthened. This notion is consistent with seminal research on control. For example, [51] points out that control represents an opportunity to exercise judgement, which enhances individuals' feelings of self-efficacy.

Moreover, job control is especially important to older persons as their capacity for primary control decreases, that is, individuals' capacity to adapt their external world to their personal needs declines with age [52]. This means that enhancing older workers' control striving through control on the job is likely to be a particularly potent motivating factor for them. In addition, past IT research has shown that control is a major factor in users' trying to innovate with IT [10]. Therefore:
H2a: The negative, indirect effect of age through creative IT-self efficacy on a user's goal to innovate with IT depends on the user's job control; specifically, the mediated relationship between age and user innovation (via creative IT self-efficacy) will be weaker for higher levels of job control.

As to support for creativity, support in general could have a negative impact on creativity if all that were asked of employees is sticking to established routines and learned behaviors [53]. However, support for creativity will have positive implications for employee creativity if it enables employees to go beyond established routines and learned behaviors. The Creativity Theory of Aging maintains that receiving a high level of support for creativity signals to employees that developing creative ideas is valued. This increases employees' motivation to be creative. In accordance with this focus on motivation, we define support for creativity in terms of extrinsic and intrinsic motivating factors, especially IT support and user enjoyment $[54,55]$.

IT support is an extrinsic motivating factor that can take various forms such as computer training, user guides, super-users, or technical specialists. Based on the Creativity Theory of Aging, we hold that IT support signals to employees that developing new ideas about how to use an IT is valued. This signal counters the negative age stereotypes that older workers often hold against themselves, especially regarding the use of technology. By contrast, lack of IT support signals to employees that developing new ideas about how to use an IT is not valued. This signal is in agreement with the negative age stereotypes that older workers often hold against themselves. Thus older workers will interpret it as a confirmation of their inability to generate novel ideas about how to use an IT. As a result, the negative impact of age on creative IT selfefficacy and innovation is strengthened. Besides, IT support can create a climate of psychological safety that encourages employees to generate new ideas. This will encourage especially older workers to use IT in creative ways [40]. Moreover, IT support can help users solve the problems that are frequently encountered during a user's goal to innovate with IT. In doing so, IT support can increase older workers' willingness to leverage their accumulated knowledge and experience in the quest of generating novel ideas about how to use an IT. Therefore:

$H 2 b$ : The negative, indirect effect of age through creative IT-self efficacy on a user's goal to innovate with IT depends on IT support; specifically, the mediated relationship between age and user innovation (via creative IT SE) will be weaker for higher levels of IT support. 
We conceptualize intrinsic motivation as users' perceived enjoyment. The basic premise is that users will be more intrinsically motivated to be creative with IT when they enjoy using the technology. Perceived enjoyment is a core element of intrinsic motivation, which is fundamental to the creative process [12]. In fact, intrinsic motivation and enjoyment are the most important factors in creative idea generation, even more important than experience and expertise [12]. In the context of IT-related work, seminal research on perceived enjoyment and technology acceptance indicate that hedonic motivation and especially user enjoyment are strongly related to IT usage and to a user's goal to innovate with IT [56,57,58,28].

At the same time, enjoyment is relevant to aging in that human beings become increasingly selective as they age [13]. As a result of their greater selectivity, they invest themselves fully in goals and activities that maximize positive emotional experiences like enjoyment. In other words, aging leads to the desire to increase enjoyment in life. Therefore, if older persons enjoy an activity, they are more likely to embark on it fully than younger persons.

Taken together, these arguments indicate that older workers who enjoy using an IT are less likely to be discouraged by negative age stereotypes. Even in the presence of age stereotypes they are more likely to seek out enjoyable and stimulating experiences like developing new ideas about how to use an IT. Thus:

H2c: The negative, indirect effect of age through creative IT-self efficacy on a user's goal to innovate with IT depends on the user's perceived enjoyment; specifically, the mediated relationship between age and user innovation (via creative IT self-efficacy) will be weaker for higher levels of perceived enjoyment.

The three mitigating factors influence the relation between age and creative IT self-efficacy rather than the link between creative IT self-efficacy and user innovation because they directly modify the extent to which age impacts creative self-efficacy.

\section{Proposed Research Method}

We will collect survey data from organizational IT users of varying ages. All respondents will be workers who use IT to accomplish their work tasks. Following recent IT research a market research company will be used for data collection. These companies offer many advantages for IT researchers, including generalizability and participant reach. We are planning to use Empanelonline, which performs sophisticated panel management, stressing verification and data quality. For example, Empanelonline uses a double opt-in process and implements knowledge-based questions to confirm that prospective respondents are qualified to take a survey. We will take additional steps to ensure data quality, for example, quality assurance questions.

All measures will be adapted from prior research. The measure for creative IT Self-efficacy will be adapted from Rahrovani and Pinsonneault [38,39]. User innovation will be measured using the scale for trying to innovate put forward by Ahuja \& Thatcher [10]. The measure for job control will be adapted from Binnewies et al. [13], and the one for IT support from Rahrovani and Pinsonneault [38]. Perceived enjoyment will be adapted from Van der Heijden [58].

\section{Expected contributions}

This research will make important contributions both to theory and to practice. For theory, we will explain why older users engage less in the postadoptive use of technologies, especially in terms of user innovation. Specifically, we will demonstrate that creative IT self-efficacy carries the effect of age on to user innovation. This explanation for the relationship between age and user innovation is based on the premise that negative age stereotypes lead human beings to feel less creative with age. Moreover, we will emphasize that job control, IT support, and user enjoyment can buffer against age-related declines in creative IT self-efficacy.

Managers will learn that fostering a culture against age stereotypes is necessary to improve post-adoptive use, especially user innovation. However, this is a daunting task that will take decades, and it's a task for society at large. In the more immediate future, managers can provide older workers with more autonomy and IT support to counterbalance the effects of negative age stereotypes, and they can invest in computer systems that older workers enjoy using.

Systems designers will learn how to design systems that older workers enjoy using. Following the ideas about increasing selectivity with age [47], there are various aspects of systems design that can make the use of a technology more enjoyable for older workers.

Perhaps the most important aspect in systems design for older users is user involvement. Designers have to include small numbers of older end users in the design and development process to learn what system characteristics they appreciate. All too often, systems are designed by younger developers who assume a similarity to the user. This assumption breaks down when systems are designed for a graying workforce, which means that getting older users involved early in the design process is extremely important to obtain their feedback and capture their special requirements. 
The systems design process should use small iterations and employ rapid prototyping methods. This will help ensure that older users' concerns are taken into account fully before a new system is deployed. As a result, older users will be more likely to enjoy using the system.

Moreover, systems should be designed such that older users can take full advantage of their crystallized intelligence, especially in terms of their vocabulary knowledge. For example, tag-based interface navigation allows users to retrieve content using keywords rather than spatial hierarchies. Given the greater vocabulary knowledge of older users combined with their reduced spatial abilities [47], they will enjoy it more to work with a tag-based system than a hierarchy-based one. This is based on the findings that 1) technologies trigger negative emotions when they are perceived as hindering performance and 2) they trigger positive emotions when they are perceived as consistent with one's own cognitive abilities [8].

Finally, aesthetics will have to be considered since they are a major factor in triggering enjoyment vis-avis technologies [58]. In particular, sensory aesthetics like screen colors and formal aesthetics such as screen layouts and screen designs can trigger positive emotions related to enjoyment [58]. For example, cooler colors like blue and green have been found to be associated with greater perceived enjoyment, whereas warmer colors such as red and yellow are generally associated with less enjoyment. This means that cooler colors can increase user enjoyment, which is an intrinsic motivator of creative IT self-efficacy. Thus cooler colors can encourage older users to seek out enjoyable and stimulating experiences like developing new ideas about how to use an IT even in the presence of negative age stereotypes.

Future research could examine such other interesting mediating factors as habit, collaborative culture performance or experiential culture. These factors could shed additional light on the relationship between age and user innovation.

\section{Conclusion}

This study focused on creative IT self-efficacy as an explanation for age-related differences in user innovation. The study further proposed three contextual factors, namely job control, IT support, and user enjoyment, as moderators of the relationship between age and user innovation.

Our model was based on the Creativity Theory of Aging [13]. Following a careful analysis of the considerations for theory adaptation laid out by Truex et al. [30], we concluded that this theory was appropriate to examine our research questions. This theory and our resulting model were also fully consistent with the conceptualization and operationalization of user innovation as a goal-based construct. This argument can be made because goals are influenced 1) by users' beliefs about their personal ability and 2) by their beliefs about the use context [10]. The explanation for age differences we identified in this paper was creative IT-self efficacy, which is a belief about one's personal ability regarding the creative use of technology for work purposes [38,39]. Further, the three moderators were beliefs about the context in which IT-related work takes place, for example regarding the extent of IT support. Therefore, our model fits the conceptualization and operationalization of user innovation as a goal-based construct.

Ultimately, all-inclusive theories should encompass all aspects of this phenomenon. Yet, an in-depth explanation of the relation between age and user innovation is by itself a formidable goal at the present time. Therefore, we believe to have made an important step toward clarifying the role of age in user innovation, and we hope that this study will lead to more work in this area to help older users like Bonnie (our opening vignette) use IT more effectively.

Still, all of us know of older users who are high performers, who outperform younger users on various aspects of IT use. We wish to emphasize that our findings hold for age in general, on average, not for every user. Our results should not be interpreted as encouraging discrimination against older users or any kind of stereotyping. This is especially true as older users also have important advantages compared to younger ones: while fluid abilities such as working memory decline with age and might hinder effective IT use, crystallized abilities like vocabulary knowledge improve with age and might facilitate older workers' IT usage. Thus, our results should be considered a means of facilitating the development of intervention strategies that can increase the productivity of a graying workforce.

\section{Acknowledgements}

This research was supported by the Social Sciences and Humanities Research Council of Canada. 


\section{References}

[1] OCDE. (2017). Labour market statistics : Labour force statistics by sex and age.

[2] Publishing, O. (2013). OECD Employment Outlook 2013: OECD Publishing.

[3] Kershaw, A. (2009). Faculty postpone retirement across Canada. University Affairs, 28.

[4] OCDE. (2011). Helping older workers find and retain jobs. In Pensions at a glance 2011:

Retirement-income systems in OECD and G20 countries (pp. 67-79).

[5] Beck, B. (2017). Older, wiser. The Economist: The World in 2018, 29-29.

[6] Benbasat, I., \& Zmud, R. W. (1999). Empirical research in information systems: the practice of relevance. MIS quarterly, 3-16.

[7] Wailgum, T. (2009, 26/02/2009). Want ot Save $\$ 10$ Million or More on ERP? Don't Buy Oracle or SAP. CIO Magazine, 2017.

[8] Jasperson, J. S., Carter, P. E., \& Zmud, R. W. (2005). A comprehensive conceptualization of postadoptive behaviors associated with information technology enabled work systems. MIS quarterly, 29(3), 525-557.

[9] Kaba, B. (2018). Information and communication technology use continuance behavioral intention: Differential effect based on socio-economic status. Paper presented at the Proceedings of the 51st Hawaii International Conference on System Sciences.

[10] Ahuja, M. K., \& Thatcher, J. B. (2005). Moving beyond intentions and toward the theory of trying: effects of work environment and gender on post-adoption information technology use. MIS quarterly, 29(3), 427-459.

[11] Tams, S., Thatcher, J. B., \& Craig, K. (2017). How and why trust matters in post-adoptive usage: The mediating roles of internal and external selfefficacy. The Journal of Strategic Information Systems.

[12] Amabile, T. M. (1988). A model of creativity and innovation in organizations. Research in organizational behavior, 10(1), 123-167.

[13] Binnewies, C., Ohly, S., \& Niessen, C. (2008). Age and creativity at work: The interplay between job resources, age and idea creativity. Journal of Managerial Psychology, 23(4), 438-457.

[14] Eder, P., \& Sawyer, J. E. (2007). A meta-analytic examination of employee creativity. Paper presented at the 22nd annual conference, society of industrial and organizational psychology (SIOP), New York, NY, April.

[15] Rothermund, K., \& Brandtstädter, J. (2003). Age stereotypes and self-views in later life: Evaluating rival assumptions. International Journal of Behavioral Development, 27(6), 549554.

[16] Schloegel, U., Stegmann, S., van Dick, R., \& Maedche, A. (2018). Age stereotypes in distributed software development: The impact of culture on age-related performance expectations.
Information and Software Technology, 97, 146162.

[17] Knowles, B., \& Hanson, V. L. (2018). The wisdom of older technology (non) users. Communications of the ACM, 61(3), 72-77.

[18] Lee, H.-J., Jeong Cho, H., Xu, W., \& Fairhurst, A. (2010). The influence of consumer traits and demographics on intention to use retail selfservice checkouts. Marketing Intelligence \& Planning, 28(1), 46-58.

[19] Hauk, N., Hüffmeier, J., \& Krumm, S. (2018). Ready to be a Silver Surfer? A Meta-analysis on the Relationship Between Chronological Age and Technology Acceptance. Computers in Human Behavior.

[20] Tams, S., Grover, V., \& Thatcher, J. (2014). Modern information technology in an old workforce: toward a strategic research agenda. The Journal of Strategic Information Systems, 23(4), 284-304.

[21] Morris, M. G., \& Venkatesh, V. (2000). Age differences in technology adoption decisions: Implications for a changing work force. Personnel psychology, 53(2), 375-403.

[22] Venkatesh, V., Morris, M. G., Davis, G. B., \& Davis, F. D. (2003). User acceptance of information technology: Toward a unified view. MIS quarterly, 425-478.

[23] Lam, J. C., \& Lee, M. K. (2006). Digital inclusiveness--Longitudinal study of Internet adoption by older adults. Journal of Management Information Systems, 22(4), 177-206.

[24] Morris, M. G., Venkatesh, V., \& Ackerman, P. L. (2005). Gender and age differences in employee decisions about new technology: An extension to the theory of planned behavior. IEEE transactions on engineering management, 52(1), 69-84.

[25] Moores, T. T., \& Chang, J. C. J. (2006). Ethical decision making in software piracy: Initial development and test of a four-component model. Mis Quarterly, 167-180.

[26] Schmitz, K., Teng, J. T., \& Webb, K. (2016). Capturing the Complexity of Malleable IT Use: Adaptive Structuration Theory for Individuals. MIS Quarterly, 40(3), 663-686.

[27] Brown, S. A., Dennis, A. R., \& Venkatesh, V. (2010). Predicting collaboration technology use: Integrating technology adoption and collaboration research. Journal of Management Information Systems, 27(2), 9-54.

[28] Venkatesh, V., Thong, J. Y., \& Xu, X. (2012). Consumer acceptance and use of information technology: extending the unified theory of acceptance and use of technology. MIS quarterly, 157-178.

[29] Venkatesh, V., Sykes, T. A., \& Venkatraman, S. (2014). Understanding e-Government portal use in rural India: role of demographic and personality characteristics. Information Systems Journal, 24(3), 249-269. 
[30] Truex, D., Holmström, J., \& Keil, M. (2006). Theorizing in information systems research: A reflexive analysis on the adaptation of social theory to information systems research. Journal of the AIS, 7(12), 797-821.

[31] Murray, J. B., \& Evers, D. J. (1989). Theory borrowing and reflectivity in interdisciplinary fields. ACR North American Advances.

[32] Murray, J. B., Evers, D. J., \& Janda, S. (1995). Marketing, theory borrowing, and critical reflection. Journal of Macromarketing, 15(2), 92106.

[33] Fiske, S. T., Cuddy, A. J., Glick, P., \& Xu, J. (2002). A model of (often mixed) stereotype content: competence and warmth respectively follow from perceived status and competition. Journal of Personality and social Psychology, 82(6), 878.

[34] Posthuma, R. A., \& Campion, M. A. (2009). Age stereotypes in the workplace: Common stereotypes, moderators, and future research directions. Journal of management, 35(1), 158188.

[35] Ng, T. W., \& Feldman, D. C. (2013). A meta-analysis of the relationships of age and tenure with innovation-related behaviour. Journal of occupational and organizational psychology, 86(4), 585-616.

[36] Snyder, M., Tanke, E. D., \& Berscheid, E. (1977). Social perception and interpersonal behavior: On the self-fulfilling nature of social stereotypes. Journal of Personality and social Psychology, 35(9), 656.

[37] Levy, B. R., Ferrucci, L., Zonderman, A. B., Slade, M. D., Troncoso, J., \& Resnick, S. M. (2016). A culture-brain link: Negative age stereotypes predict Alzheimer's disease biomarkers. Psychology and aging, 31(1), 82.

[38] Rahrovani, Y., \& Pinsonneault, A. (2014). User's Perceived IS Slack Resources and their Effects on Innovating with IT. Paper presented at the International Conference on Information Systems 2014.

[39] Rahrovani, Y., \& Pinsonneault, A. (2015). Individually Perceived IS Slack Resources and Innovating with IT. Paper presented at the System Sciences (HICSS), 2015 48th Hawaii International Conference on.

[40] Tierney, P., \& Farmer, S. M. (2002). Creative selfefficacy: Its potential antecedents and relationship to creative performance. Academy of Management journal, 45(6), 1137-1148.

[41] Bandura, A. (1977). Self-efficacy: toward a unifying theory of behavioral change. Psychological review, 84(2), 191.

[42] Compeau, D. R., \& Higgins, C. A. (1995). Computer self-efficacy: Development of a measure and initial test. MIS quarterly, 189-211.

[43] Marakas, G. M., Yi, M. Y., \& Johnson, R. D. (1998). The multilevel and multifaceted character of computer self-efficacy: Toward clarification of the construct and an integrative framework for research. Information systems research, 9(2),
126-163.

[44] Zhang, X., \& Venkatesh, V. (2013). Explaining employee job performance: The role of online and offline workplace communication networks. MIS quarterly, 37(3), 695-722.

[45] Bandura, A. (1997). Self-efficacy: The exercise of control: Macmillan.

[46] Luszcz, M. A., Bryan, J., \& Kent, P. (1997). Predicting episodic memory performance of very old men and women: Contributions from age, depression, activity, cognitive ability, and speed. Psychology and aging, 12(2), 340.

[47] Salthouse, T. A. (1991). 11 Expertise as the circumvention of human processing limitations. Toward a general theory of expertise: Prospects and limits, 286.

[48] Nyberg, L., Bäckman, L., Erngrund, K., Olofsson, U., \& Nilsson, L.-G. (1996). Age differences in episodic memory, semantic memory, and priming: Relationships to demographic, intellectual, and biological factors. The Journals of Gerontology Series B: Psychological Sciences and Social Sciences, 51(4), P234-P240.

[49] Hultsch, D. F., Hammer, M., \& Small, B. J. (1993). Age differences in cognitive performance in later life: Relationships to self-reported health and activity life style. Journal of gerontology, 48(1), P1-P11.

[50] Salthouse, T. A. (1996). The processing-speed theory of adult age differences in cognition. Psychological review, 103(3), 403.

[51] Karasek Jr, R. A. (1979). Job demands, job decision latitude, and mental strain: Implications for job redesign. Administrative science quarterly, 285308.

[52] Schulz, R., Wahl, H.-W., Matthews, J. T., De Vito Dabbs, A., Beach, S. R., \& Czaja, S. J. (2014). Advancing the aging and technology agenda in gerontology. The Gerontologist, 55(5), 724-734.

[53] Amabile, T. M., Hill, K. G., Hennessey, B. A., \& Tighe, E. M. (1994). The Work Preference Inventory: assessing intrinsic and extrinsic motivational orientations. Journal of Personality and social Psychology, 66(5), 950.

[54] Amabile, T. M. (1993). Motivational synergy: Toward new conceptualizations of intrinsic and extrinsic motivation in the workplace. Human resource management review, 3(3), 185-201.

[55] Ryan, R. M., \& Deci, E. L. (2000). Intrinsic and extrinsic motivations: Classic definitions and new directions. Contemporary educational psychology, 25(1), 54-67.

[56] Davis, F. D., Bagozzi, R. P., \& Warshaw, P. R. (1992). Extrinsic and intrinsic motivation to use computers in the workplace. Journal of applied social psychology, 22(14), 1111-1132.

[57] Agarwal, R., \& Karahanna, E. (2000). Time flies when you're having fun: Cognitive absorption and beliefs about information technology usage. MIS quarterly, 665-694.

[58] Van der Heijden, H. (2004). User acceptance of hedonic IS. MIS quarterly, 695-704. 